Chapter Title: Introducing Online Vitriol

Chapter Author(s): Sara Polak and Daniel Trottier

Book Title: Violence and Trolling on Social Media

Book Subtitle: History, Affect, and Effects of Online Vitriol

Book Editor(s): Sara Polak, Daniel Trottier

Published by: Amsterdam University Press. (2020)

Stable URL: https://www.jstor.org/stable/j.ctv1b0fvrn.4

JSTOR is a not-for-profit service that helps scholars, researchers, and students discover, use, and build upon a wide range of content in a trusted digital archive. We use information technology and tools to increase productivity and facilitate new forms of scholarship. For more information about JSTOR, please contact support@jstor.org.

Your use of the JSTOR archive indicates your acceptance of the Terms \& Conditions of Use, available at https://about.jstor.org/terms

This book is licensed under a Creative Commons Attribution-NonCommercialNoDerivatives 4.0 International License (CC BY-NC-ND 4.0). To view a copy of this license, visit https://creativecommons.org/licenses/by-nc-nd/4.0/. 


\title{
Introducing Online Vitriol
}

\author{
Sara Polak and Daniel Trottier
}

In 'How One Stupid Tweet Blew Up Justine Sacco's Life' (New York Times Magazine, 12 February 2015) Welsh journalist Jon Ronson investigated the effect on victims of public shaming through social media platforms and compared it to the history of public shaming as a form of punishment. Such punishments (the stocks, the pillory, the whipping pole) have gone out of practice, in part because they were considered too humiliating and socially annihilating for the person undergoing the punishment. Ronson finds a clear parallel in the effects of online public shaming in the victims of the present. He both interviewed victims, including Justine Sacco (famous for being shamed online by thousands of people as a racist by the malicious retweet of her 'funny' joke tweeted just before going offline on an intercontinental flight in 2013), and people who had been important in setting off such processes, like Sam Biddle, who initially retweeted Sacco's tweet and posted it on Valleywag, with the hashtag \#hasjustinelandedyet. Biddle was unapologetic in his interview with Ronson about the harm done to Sacco as a result of the Twitter storm (she was let go from her job, received numerous death threats, was socially isolated, and trauma-

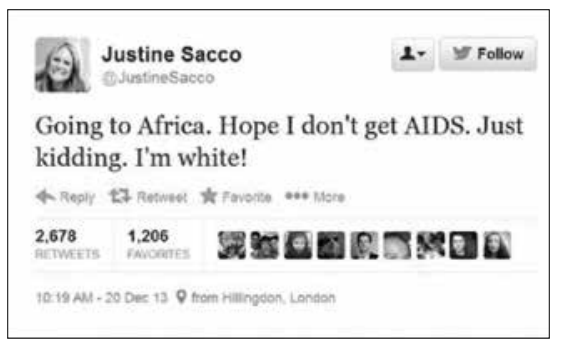
tized by the ordeal - all effects that have come to be seen as fairly typical for public shaming). ${ }^{1}$ However, Biddle later became victim of such a shitstorm himself, and a year after the initial denunciation publicly apologized to Sacco.

Ronson reflects how he himself was initially a keen actor in such processes:

1 For more research on these 'typical' effects of online shaming see e.g. Jackson et al., ‘\#GirlsLikeUs; Vaidhyanathan, Anti-Social Media; Losh and Wernimont, Bodies of Information; Lovink, Social Media Abyss.

Polak, Sara, and Daniel Trottier (eds), Violence and Trolling on Social Media. Amsterdam, Amsterdam University Press 2020 DOI: 10.5117/9789462989481_INTRO 
In the early days of Twitter, I was a keen shamer. When newspaper columnists made racist or homophobic statements, I joined the pile-on. [...] It felt as if hierarchies were being dismantled, as if justice were being democratized. As time passed, though, I watched these shame campaigns multiply, to the point that they targeted not just powerful institutions and public figures but really anyone perceived to have done something offensive. I also began to marvel at the disconnect between the severity of the crime and the gleeful savagery of the punishment. It almost felt as if shamings were now happening for their own sake, as if they were following a script. ${ }^{2}$

Sacco herself worked in PR, and Ronson and Biddle too are both journalists, writers and people who are professionally involved in communication online. Yet even as professionals they are clearly as little in control of the 'gleeful savagery' of online shaming as anyone else. At most they may be said to have a bit more agency or influence than others, ${ }^{3}$ which only underscores how unprepared and outmatched other targets might be when facing an angered online mob. ${ }^{4}$

Events like this have become very common in recent years and they raise many questions. For instance, do trolling, 'doxxing' (publicizing someone's personal details such as home address and phone number without consent), or contributing to public shaming as in the above cases constitute a form of violence? Who are its victims? And how are victims, bystanders, societies and platform owners to deal with it? Is it something that can be controlled, and if so by whom? And what is the genealogy of online vitriol? How, does it interact with embodied violence offline? While online and offline worlds seem separated, the consequences of online media expressions also occur offline, and many online dynamics have offline equivalents in past and present. Beyond comparisons to the pillory, there are many other ways in which this phenomenon resembles the online equivalent of age-old enactments of violence. Ronson, for instance, reports getting one jarring response to having set off a shaming campaign on Twitter ('amid the hundreds of congratulatory messages I received') - a question: 'Were you a bully at school?'.

2 https://www.nytimes.com/2015/02/15/magazine/how-one-stupid-tweet-ruined-justinesaccos-life.html. Accessed 21 February 2020.

3 As in Biddle's case because he had a larger platform; or as in Sacco's case because she should presumably have been better able to estimate the potential consequences of making a joke that could be understood as racist on a public platform.

4 Lovink, Social Media Abyss. 
The link between bullying and trolling on social media has often been made, for one thing because a great deal of bullying in the context of school nowadays also occurs online, but also because the setting in which trolling happens is similar to that of bullying. ${ }^{5}$ If we consider trolling to mean 'sowing discord on the internet by starting quarrels or upsetting people, by posting inflammatory, extraneous, or off-topic messages in an online community with the intent of provoking readers into an emotional response or of otherwise disrupting normal, on-topic discussion', some of the intentions and effects are obviously similar to those of bullying. In terms of social psychology the aim of either is to disrupt the communication of real or randomly selected 'enemies', in order to strengthen a sense of power within one's own group. Social media platforms like Twitter, Facebook or Reddit are especially fertile environments for this, because conversation there, even if it seems to be between two people, is really also a performance for the benefit of perhaps very many invisible onlookers, who may or may not express themselves through likes, retweets, or by adding comments. ${ }^{6}$ Thus, such a conversation, which might have been entirely civil if it happened face to face between two people, or even in a series of one-on-one direct messages, can easily become like a schoolyard fight. The function most of the comments serve is rather to show off one's acerbic wit or cool to people on one's own side, rather than to arrive at mutual understanding or appreciation. As in offline bullying then, the function of such 'debates' is often rather to strengthen one's own 'ingroup' by means of excluding and humiliating the opponent. Thus, the 'normal on-topic discussion' is often less the logical function of social media exchanges, than the disruption itself, which may have a range of secondary purposes, such as entertainment, silencing political opposition, a sense of power for those doing the targeting, or of safety for those not targeted.

Many social media platforms through their design - the publicness of communication, the possibility to share, like, and comment on earlier statements, the imposed brevity of such statements - facilitate processes of group formation through bullying and exclusion more easily than they facilitate conversation that brings insight into the content of what is being discussed. This is also why two factions clashing on social media platforms can often both come away from the exchange feeling that they are being trolled by the others. Similarly, there are various cases where the person who

5 Wright (ed), A Social-ecological Approach to Cyberbullying; Horowitz and Bollinger, Cyberbullying.

6 Settle, Frenemies. 
(is perceived to have) started the public shaming of someone, is later targeted in the same way and with the same effects by anonymous wrath. And while this wrath seems volatile, and online abuse may happen to anyone, there is ample evidence that misogyny and other forms of vitriol aimed at minorities thrive online both in terms of quantity and sheer bluntness of such utterances.

This book is motivated by a series of urgent questions surrounding online vitriol. Even in a deeply polarized political climate, one common experience across the spectrum is the sense of simultaneous empowerment and powerlessness in response to prolific and persistent digitally mediated communications. We are wondering how to evaluate, and what to do with, the overwhelming amount of such activity, much of which can be considered violent. What is online vitriol, as we have termed it throughout the book? What does it mean? What is its intent? In what ways is this phenomenon new compared to forms of violence or vitriolic texts in the broadest sense from the past? How productive, in this context, is the dichotomy of online and offline? And how can individuals, organizations, (media) companies and governments respond to it? ${ }^{7}$

These important and urgent questions bring together scholars in the social sciences and humanities, as well as activists and media professionals who through their work are regularly confronted with online vitriol. Their discussions are reflected in this book, which seeks to bridge academic research and everyday practice. We take this approach since online vitriol arguably has an impact on all of us, even those who choose not to participate in online social networking. And many professionals, for instance in journalism, communications or politics, no longer have the luxury of being able to avoid social media altogether.

The notion of online vitriol is a complicated one. When can online sociality be considered as violence, and to what extent can this be determined objectively? Whitney Phillips and Ryan Milner in their book The Ambivalent Internet explicitly embrace the notion of ambivalence here, arguing that what can be offensive to one reader is funny to another. ${ }^{8}$ Of course this is true, and their appreciation of the ambivalence and the sliding scale of what is possible or acceptable is an essential element of a great deal of online sociality. However, we position ourselves on the side of those negatively affected by online expressions in a way that can be construed as violent. In

7 Several strategies for doing this are discussed in Sunstein, \#Republic and in Caplan et al., 'Algorithmic Accountability'.

8 Phillips and Milner, The Ambivalent Internet. 
other words, our primary focus is precarity and relative powerlessness in the face of online vitriol, which characterizes the experience for instance of a trans activist whose home address and/ phone number are publicized online, or of the female critics who were victimized by GeenStijl (a Dutch online news website that posted photos of critical columnists, asking their readers to respond in the comments to the question 'Would you do her?'). However, the business models driving such sites' editors and the affective or political motivations of their anonymous posters are also considered.

The first question to answer is how we should read potentially violent messages on social media. Throughout its chapters this book is committed to showing that these are speech acts, in the sense that they are in various ways performative. By saying or showing something, they do something. This is not new to social media networks: a threat exists only in words, yet it can profoundly alter the reality of safety of the person threatened. This is true whether the threat is uttered on Twitter or a handwritten letter, but the difference is that on social media, users are typically less inhibited by social norms and practical viability to utter threats, which to them may seem silly or trivial, but not to the receiver, in the characteristic ambivalence that Phillips and Milner analyze. Nonetheless, a threat, however ephemeral in the eyes of the sender, remains performative in J.L. Austin's sense of the term: ${ }^{9}$ like speech acts such as 'I promise', it changes the reality. Online speech acts can also be performative in a considerably more aggressive way, for instance, when they serve to retweet or otherwise spread nude photos without the consent of the (often famous) person photographed. A share or retweet may seem inconsequential enough to the user clicking the button, but it is precisely the massive spread of such images that actually constitutes and continues the abuse implicit in the non-consensual spread of the image.

\section{What is online vitriol?}

Various terms are in use to describe violent, bullying, demeaning, or otherwise antagonistic expressions on social media platforms. Hate speech is common, but also not limited to the online world. While it does signal that these expressions are speech acts, and therefore, as we maintain, performative, the reference to 'hate' does not always seem justified. While many different motivations and affects can be involved, and hatred on the part of the sender is surely one of them, other motivations exist too 
(as considered for instance in chapters two, three and seven). The term is thus both too broad and too narrow in its seeming attribution of motives. Feminist scholar Emma Jane has introduced the term 'e-bile', which is useful, but particularly designed for the specific category of misogynist and objectifying comments addressed to women online. ${ }^{10}$ We propose online vitriol as a term to think about this phenomenon, because it stresses both the violent and the uncontrollable aspects of the phenomenon and its typical excesses, such as shitstorms, and speech acts that silence, threaten, or harm others.

Etymologically vitriol derives from the Latin 'vitriolum' which means sulphuric acid, and is akin to the Latin word 'vitrum', glass. In common usage it means bitter or abusive speech or malice. Vitriol does tend to be acidic and acerbic, and the metaphor of splintering glass is apt in this context. Moreover, vitriol is a word as well as a phenomenon with long cultural roots in the Western world. Vitriol has been expressed and documented in historical contexts, as Frans-Willem Korsten and Ewelina Pepiak show in Section Two.

Online vitriol seems to be a particular product of the Web 2.0, the 'participatory' or 'social web' that has evolved since the early twenty-first century, and that revolves around 'user-generated content' and conceives of the web as a space of interaction, rather than a collection of static sites where one can read information. The term 'Web 2.0' was coined in 1999 by Darcy DiNucci in an article prophetically titled 'Fragmented Future.. ${ }^{11}$ Fragmentation does indeed seem to be one of the key aims and effects of online vitriol enabled by the interactive structure of social media platforms. In recent years particularly, online vitriol has come to serve political powerplay, with actors often operating from a stance of victimhood and supposed powerlessness, while at the same time attracting considerable attention, visibility and influence. This becomes manifest for instance in the context of political strife, between political actors, but also between political and press actors (Donald Trump's lashing out at mainstream media networks comes to mind as an obvious example). These are well-documented instances of vitriolic exchanges between public figures. We may consider whether these shape individuals' understandings of what is possible and what is appropriate in public discourse, though social platforms and mobile devices users can also reproduce and exceed the kinds of vitriol they encounter in public. 
Vitriol is a fruitful and troubling term to invoke when discussing the problematics of contemporary communication practices. Seemingly, the purpose is not only to cause offence or harm towards the interlocutor. Whether discussing a spat between political rivals or a heated exchange between cultural influencers on Twitter, the intention is simultaneously to communicate a disregard for that target - as well as the categories and communities to which they may belong - to a wider audience. Contemporary mediated vitriol is always a public affair that is usually meant to challenge the social standing of the other, and to reassert one's own. The cases considered in this book vary in terms of political, cultural and historical contexts. Yet throughout them we may consider some common tendencies that provide insight about the harms and other consequences of vitriolic practices.

Online vitriol is weaponized: vitriol is deliberately leveraged to target political opponents, or groups that may face categorical and systemic forms of oppression. It is thus possible to consider vitriol as purpose driven: as a form of expression in which the speaker/author seeks to harm or assert one's self over someone else. This can but does not necessarily stand in contrast to an understanding of vitriol as primarily affect-driven. ${ }^{12}$ While the author of vitriolic content may be fuelled by their own disgust or hatred, perhaps of greater concern is their ability, and apparent desire, to foster and mobilize the disgust and hatred of their audience. This may be evident when assessing polarized political landscapes, but can also be observed within subcultures such as among authors and fans of young adult literature. ${ }^{13}$

Online vitriol is also prominent: the intention and effect of vitriolic statements is often to grab attention, to get clicks, to direct media focus towards oneself, and/or a target. Social media platforms are often complicit in this, as their business models depend on a steady flurry of user engagements and disclosures. The purpose is not simply to speak to the person deemed worthy of vitriol, but rather to make that denunciation visible and legible to a broad audience. In other words, vitriol is directed towards a target, but is also keenly aware of the broader public it is attempting to influence. This extends from the weaponized nature of vitriol: it's not just that the words cause harm on their own, but rather harm is yielded in making those words so visibly linked to the reputation of a targeted victim. Online vitriol can often be mobilized at remarkable speed, and thus can spread 
far and wide in little time. This does not only intensify the harm caused, but simultaneously divides responsibility for this harm among so many, often anonymous, participants, that it becomes very difficult to attribute responsibility to individuals.

Finally, online vitriol is retained: by operating through social media platforms it forms a kind of public record that may lead to unanticipated consequences. Vitriolic statements are uttered in particular contexts, and despite their seeming ubiquity, are not necessarily meant to transcend and endure beyond these contexts. Yet as digital content, vitriol can potentially (and following default settings on platforms, by default) be retained indefinitely. Produced and retained in such conditions, they will surely leak beyond their intended audience, and new standards of acceptability may inform how they are received by temporally and spatially dispersed publics. For this reason, researchers and other professionals must remain attentive to prominent and routinized forms of vitriol, especially as these become acceptable practices both within and beyond particular contexts.

\section{Purpose of the book and overview of the sections and chapters}

This book considers online vitriol in a context of significant mediatization in a new and rapidly changing media ecosystem, in which data are collected and processed in ways that are difficult for individual users to oversee, but also difficult for lawmakers to regulate and enforce. This book brings together disciplines, such as digital media studies, cultural history, and literary studies. It both uses the tools and analytical apparatus from older disciplines to understand new developments in their historical and cultural context, and it offers new terminology and case studies to think through the ways in which online vitriol functions in ways fundamentally different from older structures and dynamics of vitriol. This book also brings together perspectives and contributions that go beyond a purely scholarly interest, including activist and journalistic engagements. This contributes in particular to a consideration of vitriol's societal importance, and steps that readers can take when encountering it. We hope that this book is also, or perhaps primarily, of interest to people who do not necessarily study online vitriol, but who are in their daily work and life confronted with its practices.

This book is comprised of four sections, each providing various perspectives on one of the book's guiding questions. The first part on the dynamics 
of online vitriol concerns the question how online vitriol works in ontological and medial terms. How do social media networks lend themselves to digital vigilantism, or to the spreading of 'scares', and how should one respond to trolls? The second section is dedicated to the historical precursors of online vitriol and to the online life of cultural memory. Where in the offline past does online vitriol find its roots? And how is it new? The third section is dedicated to the affects of online vitriol. How does online sociality and vitriol incite waves of strong affective responses? How does this 'economy' of affect work for and in online platforms and carry over into traditional tabloid media? What sensibilities drive online activism from the Alt-Right? And to what extent must online vitriol be considered 'onlife' in the sense that it has tangible effects in the offline world? The final section is dedicated to activism, and is written by activists, with academic backgrounds, who explain how they personally and collaboratively deal with the vitriol aimed at them in response to their work, what initiatives exist to protect users, by users themselves, governments, platforms, and other organizations and collectives. This section clearly shows the inextricability of the online and the offline.

How are social dynamics in the public sphere different if that public sphere is largely moved to an online environment? The opening chapter by Trottier, Gabdulhakov and Huang discusses the issues of citizens' vigilantism (watching and calling out each other's real and perceived impolite or uncivil behaviour in public space) when this happens in the online world. The chapter addresses case studies in three different countries (the UK, Russia, and China), showing how these are each culturally specific yet escalate the impact for those who are at the receiving end of this 'digilantism'.

Tom Clucas's chapter addresses practices of YouTube users calling each other out in the comments for racist or trolling behaviours. The chapter gives historical and philosophical context to the longstanding dilemma whether one should 'feed the trolls' or not. While the common wisdom is not to give attention to trolling - because attention is exactly what trolls presumably want - Clucas argues that many trolling comments do merit clearly denunciatory responses, and providing these is a kind of labour that the online public sphere needs.

In the third chapter Sara Polak zooms in on the early formation of political constituencies online. Some such groups, formed and mobilized through online platforms, started to become politically active well before they were easily visible a such to a larger public. The case study developed in the chapter is that of Donald Trump's and others' alarmist tweeting about the Ebola epidemic in West Africa (2013-2015) which was one of the moments Trump 
and online constituencies around him came into their own as a group and learned to hone and employ massive influence through Twitter and other online platforms that later came in handy for the formation of collectives such as Trolls for Trump (active in the 2016 Presidential campaign).

The fourth chapter, by Frans-Willem Korsten, opens the section on the histories of online vitriol, and thus attends mainly to offline dynamics and characteristics of vitriol, locating the god Momus and his daughter Rumor as European cultural forebears. Korsten makes clear that the speed with which online vitriol can spread, creates a kind of surplus value usually directed towards disrupting the process of political agonism. Thus, he argues, using the example of rapidly mass-printed pamphlets in the Dutch Republic in the $17^{\text {th }}$ century, as well as 'Alt-Right' memes of more recent date, have a crucial role in firing up political escalations beyond what is manageable in a democratic context.

Ewelina Pepiak's chapter focuses on the history of the visual rhetoric used in nationalist and racist memes employed to frame the attacks on women in Cologne on New Year's Eve 2016-7 as a reason to exclude and criminalize refugees and non-white men in general. The chapter shows that such 'memes', although they are image-text hybrids of a kind specific to social media contexts, come out of a long tradition of visual culture with stock figures and tropes to stress the danger of the colonial other as a sexualized threat to white femininity.

The sixth chapter, by Gerlov van Engelenhoven, focuses also on the presence of colonial inheritances, but rather the other way around: it studies how social media communities (Facebook groups and online fora), respond to a documentary film that has effectively become a site of memory for postcolonial trauma. Perhaps counterintuitively, Van Engelenhoven notes that the documentary allows for more nuance and a broader variety of perspectives than the social media discourse following it. Social media, despite their interactive nature, seem to allow more easily for an echo chamber of congealed memories than for actively working through a contested past.

Part three, on the affects of online vitriol, opens with Greta Olson's introduction to affect theory in general, explaining its genealogy as a preverbal visceral response, followed by her analysis of the functions of vitriolic misogyny in certain US American 'meninist' circles. Olson analyzes the meanings and implications of misogynist social media vernacular such as 'basic bitch' and concludes that this does not indicate a genuine hatred for women, so much as a collective sense of nostalgia and loyalty among men. 
The more Trump, for instance, is criticized the more fervent his supporters become in their defence of him, because he reflects their own affective experience of being beleaguered.

Ann-Marie Riesner's chapter, then, traces the affects, turning into full-blown shitstorms, that Austrian author Stefanie Sargnagel arouses through her provocative blogposts. Riesner analyzes how Sargnagel as part of her artwork manipulates her readers to expose the affective networks of vitriolic hatred that span both the online and the offline world. The analysis uses methods originating in literary studies to untangle the dynamics of online vitriol and elucidate the functioning mechanisms of online hate speech.

This notion of affect 'flowing' between the online and offline world and destabilizing any dichotomy between the two that may or may not have existed in the past, is then further explored in Katleen Gabriels and Marjolein Lanzing's chapter on 'onlife' vitriol. This chapter explores three case studies from different contexts in which online bullying and vigilantism have very tangible effects on people's lives (including suicide and being forced to move homes). Gabriels and Lanzing make a clear case that online and offline practices and sociality are so intertwined and interdependent that the online/offline binary really collapses and should be considered an 'onlife' dynamic, rejecting any notion that online vitriol can be dismissed as something limited to a specifically virtual sphere that is voluntarily entered.

The final two chapters are dedicated to activism and practice. They essentially each offer experiences and advice from activists. The first is Sophie Schwarz's reflection on her project at Justus Liebig Universität Giessen 'Why I Need Feminism' - unlike the original project that inspired this one, a specifically offline invitation to people in the university to leave their thoughts about why they need feminism. This drew serious reactions but also attracted a considerable deal of abuse, online as well as offline, surprising perhaps if one considers the offline design of the project.

In the last chapter, Penelope Kemekenidou discusses her extensive experience with online and offline feminist activism, and particularly the ways in which she and her peers protect themselves against threats and sexist violence directed against them. While this contains a wealth of rules of thumb for individual and collective self-care on social media, it also dissects how and why the corporations who own the platforms are uninterested in making them safer by setting and policing clearer boundaries of what is acceptable. 


\section{Works cited}

Austin, J.L. How To Do Things With Words. Oxford: Clarendon Press, 1976.

Caplan, Robyn, Joan Donovan, Lauren Hansen, and Jeanna Matthews. 'Algorithmic Accountability' Report. Data and Society, 18 April 2018, https://datasociety.net/ library/algorithmic-accountability-a-primer/. Accessed 1 March 2020.

DiNucci, Darcy. 'Fragmented Future'. Print Magazine, vol. 53, no. 4, 1999, pp. 32 [and] 221-222.

Gregg, Melissa. 'On Friday Night Drinks: Workplace Affects in the Age of the Cubicle', in The Affect Theory Reader, edited by Melissa Gregg and Gregory Seigworth. Durham (NC): Duke University Press, 2010, pp. 250-268.

Horowitz, Merle, and Dorothy Bollinger. Cyberbullying in Social Media within Educational Institutions: Featuring Student, Employee, and Parent Information. Lanham: Rowman \& Littlefield, 2014.

Jackson, Sarah J., Moya Bailey, and Brooke Foucault Welles. ‘\#irlsLikeUs: Trans Advocacy \& Community Building Online'. New Media \& Society, 2017, https:// journals.sagepub.com/doi/10.1177/1461444817709276.

Jane, Emma Alice. "Your a Ugly, Whorish, Slut': Understanding E-Bile'. Feminist Media Studies, vol. 14, no. 4, 2014, pp. 531-545.

Losh, Elizabeth, and Jacqueline Wernimont (eds). Bodies of Information: Intersectional Feminism and Digital Humanities. Minneapolis: University of Minnesota Press, 2018.

Lovink, Geert. SocialMedia Abyss: Critical Internet Cultures and the Force of Negation. Cambridge (UK): Polity Press, 2016.

Phillips, Whitney, and Ryan Milner. The Ambivalent Internet: Mischief, Oddity, and Antagonism Online. Malden (MA): Polity Press, 2017.

Settle, Jaime. Frenemies: How Social Media Polarizes America. Cambridge (UK): Cambridge University Press, 2018.

Sunstein, Cass. \#Republic: Divided Democracy in the Age of Social Media. Princeton: Princeton University Press, 2017.

Vaidhyanathan, Siva. Anti-Social Media: How Facebook Disconnects Us and Undermines Democracy. Oxford: Oxford University Press, 2018.

Wright, Michelle F. (ed). A Social-ecological Approach to Cyberbullying. New York: Nova Publishers, 2016. 


\section{About the authors}

SARA POLAK (Leiden University Centre for the Arts in Society) is assistant professor in American Studies, focusing on US presidents and their media. She wrote "This is Roosevelt's World" - FDR as a Cultural Icon in American Memory (Johns Hopkins University Press, 2021) and co-edited Embodying Contagion: The Viropolitics of Horror and Desire in Contemporary Discourse (University of Wales Press, 2021). She currently focuses on Trump's Twitter use. Polak teaches American literature, culture and history, and regularly comments on US politics and culture in Dutch media.

Daniel Trottier is an Associate Professor of Global Digital Media in the Department of Media and Communication at Erasmus University Rotterdam, the Netherlands. His current research considers the use of digital media for the purposes of scrutiny, denunciation and shaming. Daniel is the PI of a five-year NWO-funded project on this topic, entitled "Digital Vigilantism: Mapping the terrain and assessing societal impacts". He has authored several articles in peer-reviewed journals on this and other topics, as well as Social Media as Surveillance (Ashgate, 2012), Identity Problems in the Facebook Era (Routledge, 2013), and Social Media, Politics and the State (co-edited with Christian Fuchs; Routledge, 2014). Daniel completed a PhD in Sociology at Queen's University in Kingston, Canada. 
This content downloaded from 62.195.100.130 on Fri, 05 Feb 2021 15:01:37 UTC All use subject to https://about.jstor.org/terms 